\title{
BIOCONVERSÃO DE HIDROLISADOS HEMICELULÓSICO E CELULÓSICO DA TORTA DE MACAÚBA (Acrocomia aculeata) EM ETANOL E XILITOL POR Candida boidinii UFMG14
}

Pereira, J.B. ${ }^{1}$; Monteiro, A.L. ${ }^{1 *}$; Gonçalves, D.B. ${ }^{1}$; Oliveira, J.S. ${ }^{1}$; Santos,

$$
\text { V.L. }{ }^{2}
$$

\footnotetext{
1Departamento de Bioquímica, Universidade Federal de São João Del-Rei, Divinópolis/MG 2 Departamento de Microbiologia, Universidade Federal de Minas Gerais, Belo Horizonte/MG.

*E-mail: amtmonteiro178@hotmail.com
}

\section{Resumo}

A produção de etanol celulósico tem conquistado um lugar de destaque no desenvolvimento de novas tecnologias e tem como desafio a obtenção de hidrolisados que apresentem concentrações adequadas de açúcares. No presente trabalho, avaliou-se a bioconversão de xilose e glicose a etanol a partir de hidrolisados de torta de macaúba (Acrocomia aculeata) pela levedura Candida boidinii UFMG14. O hidrolisado hemicelulósico foi obtido por hidrólise ácida com $\mathrm{H}_{2} \mathrm{SO}_{4}$ 0,8\% (v/v) na relação sólido:líquido (1:10) da torta de macaúba e detoxificado com carvão ativado 2,5\% (p/v). O hidrolisado celulósico foi obtido por hidrólise enzimática. Para a fermentação, a linhagem foi cultivada por $72 \mathrm{~h}$, em frascos Erlenmeyer contendo hidrolisados e suplementos. Realizou-se um experimento de mistura (delineamento simplex-centroide, DSC) dos hidrolisados celulósico e hemicelulósico em diferentes proporções cuja soma resultou sempre em $1(100 \%)$. A maior produção de etanol (11,3g/L) ocorreu no ensaio 1 na proporção $100 \%$ do hidrolisado celulósico. Os ensaios 2 e 6, nos quais foram usadas as maiores proporções $100 \%(6,1 \mathrm{~g} / \mathrm{L})$ e $75 \%(7,4 \mathrm{~g} / \mathrm{L})$, respectivamente de hidrolisado hemicelulósico, apresentando produção de etanol inferior aos outros ensaios. Os resultados mostraram que o uso do hidrolisado celulósico é significativamente mais efetivo para produção de etanol nas proporções avaliadas, mostrando o potencial de $C$. boidinii UFMG14 para a produção de etanol celulósico. 
Palavras chave: Macaúba, C. boidinii UFMG14.

Apoio financeiro: CNPq, FAPEMIG.

Pereira, J.B.; Monteiro, A.L.; Gonçalves, D.B.; Oliveira, J.S.; Santos, V.L.; "BIOCONVERSÃO DE HIDROLISADOS HEMICELULÓSICO E CELULÓSICO DA TORTA DE MACAÚBA (Acrocomia aculeata) EM ETANOL E XILITOL POR Candida boidinii UFMG 14", p. 29-30 . In: Anais da V Jornada Acadêmica Internacional de Bioquímica [= Blucher Biochemistry Proceedings, v.1, n.1]. São Paulo: Blucher, 2015. DOI 10.5151/biochem-jaibqi-0039 